\title{
PURA-related severe neonatal hypotonia- seizures-encephalopathy syndrome due to a point mutation
}

INSERM

\section{Source}

INSERM. (1999). Orphanet: an online rare disease and orphan drug data base. PURArelated severe neonatal hypotonia-seizures-encephalopathy syndrome due to a point mutation. ORPHA:438216

PURA-related severe neonatal hypotonia-seizures-encephalopathy syndrome due to a point mutation is a rare, genetic neurological disease, with a highly variable phenotype, typically characterized by neonatal hypotonia, respiratory and feeding difficulties, global development delay (often with nonverbal and frequently non-ambulatory progression) and myopathic facies. Other frequently present features include seizures (or seizure-like episodes), visual impairment and encephalopathy. 